\title{
Innowacje technologiczne firmy PANASONIC w zrobotyzowanym spawaniu cienkich elementów metalowych na przykładzie wdrożeń firmy TECHNIKA SPAWALNICZA
}

\author{
PANASONIC technological innovation \\ in robotic welding of thin metal parts \\ on example implementation of TECHNIKA SPAWALNICZA
}

\section{Streszczenie}

Artykuł przedstawia nowoczesne rozwiązania zrobotyzowanego spawania metodą TIG oraz MAG metalowych elementów cienkościennych. Dla przykładu posłużono się systemami zaimplementowanymi w przemyśle motoryzacyjnym i meblowym.

Słowa kluczowe: robot spawalniczy, TAWERS ACTIVE WIRE, cienkie blachy, 7 oś robota

\begin{abstract}
This article presents new high-tech solution in robotic TIG and MAG welding of thin metal components. For example shown robotic systems implemented in automotive and furniture industry.
\end{abstract}

Keywords: welding robot, TAWERS ACTIVE WIRE, thin plate$\mathrm{s}, 7$-axis of robot

\section{Wstęp}

W procesach spawalniczych występujących w branży motoryzacyjnej, przy produkcji mebli metalowych, łóżek szpitalnych itp. zachodzi konieczność spawania elementów o coraz mniejszych grubościach. Dotyczy to zarówno stali stopowych, niestopowych oraz aluminium i jego stopów.

Łączenie elementów cienkościennych o grubości poniżej $2 \mathrm{~mm}$. wymusza wprowadzanie do złącza spawanego jak najmniejszej ilości ciepła w celu uniknięcia przepalenia lub odkształceń termicznych materiału. Aby kontrolować ten proces należy odpowiednio sterować energią liniową będącą miarodajnym odpowiednikiem wykonania poprawnej spoiny, to dzięki niej uzyskujemy prawidłowe wtopienie w głąb materiału, nagrzanie spoiwa oraz obszaru przylegającego. Oprócz nagrzewania istotna jest również szybkość wychładzania elementów spawanych ponieważ obydwa te czynniki mają w konsekwencji odwzorowanie we właściwościach wytrzymałościowych złącza. Energię liniową można opisać poniższym wzorem.

$$
E=\frac{U * I * \eta}{V}\left[\frac{J}{m m}\right]
$$

U to napięcie łuku [V], I to natężenie prądu spawania [A], V to prędkość spawania [mm/s], n to współczynnik sprawności nagrzewania.

Wymagania stawiane nowoczesnym urządzeniom powodują, że zmiana wartości z powyższego wzoru może okazać się niewystarczająca. Potrzebne są specjalistyczne aplikacje które pomogą zwiększyć poprawność i efektywność spawania cienkich elementów metalowych. Naprzeciw tym trudnościom wyszła firma PANASONIC specjalizująca się w produkcji urządzeń spawalniczych od lat 50-tych ubiegłego wieku. Obecnie firma skupiła się na robotyzacji procesów spawania i stale podnosi poziom zaawansowania technologicznego swoich produktów. Wszystkie opisane w niniejszej publikacji aplikacje zostały zaimplementowane we wdrożonych przez firmę TECHNIKA SPAWALNICZA systemach zrobotyzowanych.

\section{Narzędzia wspomagające spawanie elementów cienkościennych}

\section{Nowa generacja robotów serii TM}

W roku 2014 miała miejsce polska premiera innowacyjnej serii TM robotów firmy PANASONIC. Seria ta dedykowana jest wyłącznie do spawania. Posiada mechanizm pozwalający prowadzić drut spawalniczy w bardziej dogodny sposób przez pierwszą oś obrotową ramienia, co eliminuje konieczność stosowania balanserów. Tak innowacyjne rozwiązanie sprawia, że drut trafiając do miejsca spawania nie zakrzywia się, zwiększa to dokładność układania spoin o wąskim licu przy spawaniu cienkich elementów oraz zmniejsza zużycie końcówek prądowych (podawanie zakrzywionego drutu powoduje szybsze zużycie końcówki) [1].

Inż. Mirosław Nowak (IWE); mgr inż. Daniel Wiśniewski (IWE); mgr inż. Jacek Buchowski; mgr inż. Karol Jędrzejak - Technika Spawalnicza.

Autor korespondencyjny/Corresponding author. jacek.buchowski@techspaw.com.pl 
a)

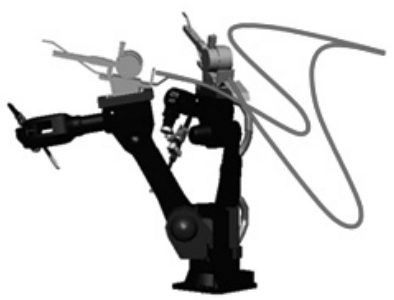

b)

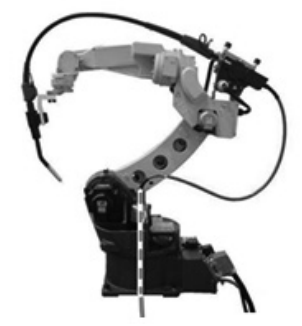

c)

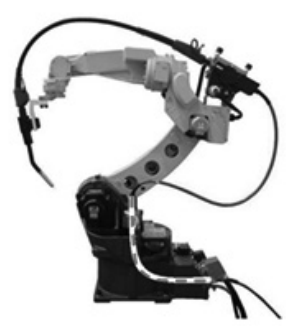

Rys. 1. Warianty prowadzenia drutu spawalniczego do podajnika drutu; a) standardowe prowadzenie drutu, b) prowadzenie drutu w pionie przez pierwszą oś robota, c) prowadzenie drutu w poziomie przez pierwszą oś robota

Fig. 1. Types of feeding welding wire do the wire feeder; a) standard type of wire feeding, b) wire feeding through first axis in vertical location, c) wire feeding through first axis in horizontal location

Aplikacje z robotami na torze jezdnym wykluczają użycie dodatkowych konstrukcji podtrzymujących prowadnik drutu oraz balanserów za ramieniem robota. $W$ tym przypadku idealnym rozwiązaniem było zastosowanie prowadzenia drutu przez pierwsza oś obrotową robota (rys. 2.) - znacznie skraca to odległość prowadzenia drutu pomiędzy szpulą z drutem, a podajnikiem drutu, przekłada się to na płynne, bezoporowe podawanie drutu, bardzo istotne podczas wykonywania dużej ilości krótkich spoin sczepnych. Wdrożona przez firmę TECHNIKA SPAWALNICZA aplikacja w firmie WIŚNIOWSKI w Nowym Sączu, przeznaczona do spawania bram przemysłowych $w$ których łączona jest metalowa rama z siatką (rys. 2.) [1] z powodzeniem wykorzystuje zalety prowadzenia drutu przez pierwszą oś.

Kolejną innowacja, jest dowolność prowadzenia pakietu spawalniczego połączonego z palnikiem, który można ukryć w całości wewnątrz ramienia robota, prowadzić poza ramieniem lub w opcji trzeciej (hybrydowej) przewód prądowy zamontować wewnątrz ramienia natomiast drut spawalniczy w miękkim prowadniku zainstalować poza nim (rys. 3) [2]. Opcje te dedykowane są do różnych aplikacji spawalniczych, przedstawionych poniżej.

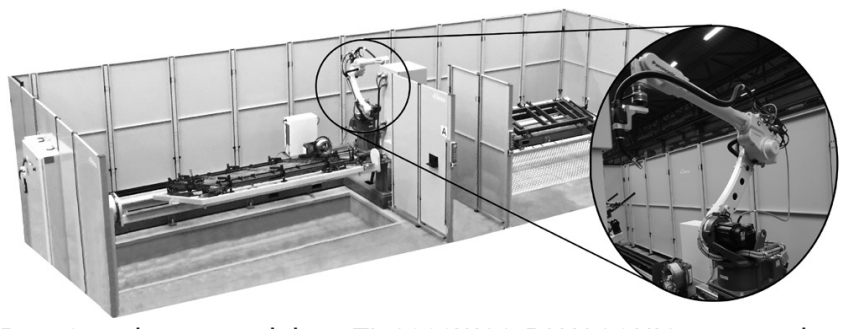

Rys. 2. Robot spawalniczy TL-2000WG3 PANASONIC z prowadzeniem drutu przez pierwszą oś obrotową ramienia, osadzony na elektrycznym torze jezdnym

Fig. 2. TL-2000WG3 PANSONIC welding robot with wire guide pass through the first axis, mounted on electric track motion a)

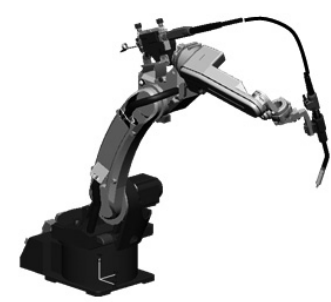

b)

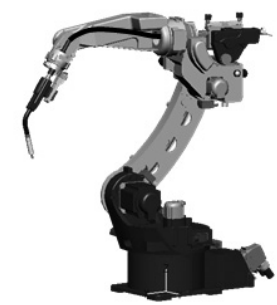

c)

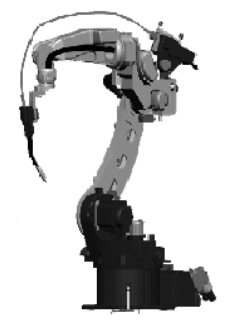

Rys. 3. Możliwości prowadzenia pakietu spawalniczego na ramieniu robota; a) standardowe mocowanie pakietu przewodów na zewnątrz ramienia, b) mocowanie pakietu wewnątrz ramienia, c) rozwiązanie hybrydowe w którym przewód prądowy prowadzony jest wewnątrz ramienia, natomiast drut spawalniczy na zewnątrz

Fig. 3. Methods of mounting welding set on robot arm; a) standard type outside of the robot arm, b) interior type, c) hybrid type in which power cable is inside robot arm and welding wire is outside

Rozwiązanie w którym pakiet jest mocowany w całości poza ramieniem (Rys. 3a) jest bardzo uniwersalne i wykorzystywane w przemyśle jako standardowe. Jedyną niedogodnością jest zawijanie się pakietu przewodów dookoła ramienia podczas obrotu ostatniej osi robota o kąt $360^{\circ}$ i większy. Drugi sposób prowadzenia przewodów wewnątrz ramienia (Rys. 3b) daje większe pole pracy w ciasnych przyrządach spawalniczych gdzie przestrzeń ruchu może być ograniczona. Wadą tego rozwiązania jest to, że punkt TCP palnika nie znajduje się w przedłużeniu szóstej osi robota co utrudnia pisanie programu $z$ obrotem nadgarstka w osi pionowej. Trzeci rodzaj, czyli rozwiązanie hybrydowe

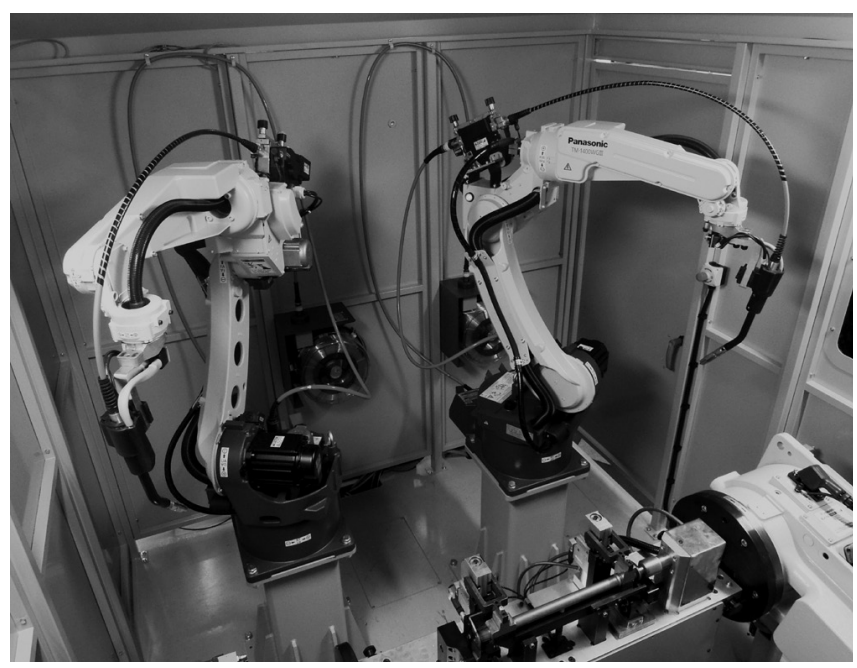

Rys. 4. Roboty spawalnicze $w$ trybie kooperacji, wyposażone w miękkie prowadniki drutu

Fig. 4. Welding robots in cooperation mode equipped with soft wire guides 
(rys. 3c) jest połączeniem zalet dwóch poprzednich metod, dając łagodną krzywiznę prowadzenia drutu w miękkim prowadniku nie usztywnionym przez przewód prądowy (rys. 4). Trudniejszy do zgięcia przewód prądowy w tym przypadku został przeprowadzony wewnątrz ramienia manipulatora przez środek ostatniej osi. Wykorzystanie miękkiego prowadnika pozwala na ustawienie ramienia robota blisko przyrządów spawalniczych lub innych robotów pracujących w trybie kooperacji, a jego zgięcie nie powoduje kolizji ani błędów w podawaniu drutu. Takie rozwiązanie jest zazwyczaj wykorzystywane w przemyśle motoryzacyjnym do spawania cienkościennych elementów o grubości poniżej $2 \mathrm{~mm}$. ponieważ umożliwia precyzyjne podawanie spoiwa. Opisane rozwiązanie zastosowano w systemie zrobotyzowanym wdrożonym przez firmę TECHNIKA SPAWALNICZA w jednej $z$ firm produkującej elementy foteli samochodów osobowych (rys. 4). W tej aplikacji dwa roboty pracujące $w$ trybie kooperacji zostały wyposażone $w$ hybrydowe pakiety przewodów.

\section{ACTIVE WIRE PROCESS}

Następnym narzędziem dedykowanym do spawaniem ultra cienkich materiałów ze stali stopowych i niestopowych jak również do spawania detali, w których nie jest zalecane wprowadzanie dużej energii liniowej jest system ACTIVE WIRE PROCESS w skrócie AWP (metoda aktywnego podawania drutu) [3]. System ten wychodzi naprzeciw problemom pojawiającym się w przemyśle motoryzacyjnym, gdzie wymagana jest duża prędkość spawania, estetyka wykonywanych połączeń, a także tam gdzie występuje ryzyko przepalenia materiału o grubości poniżej $2 \mathrm{~mm}$.

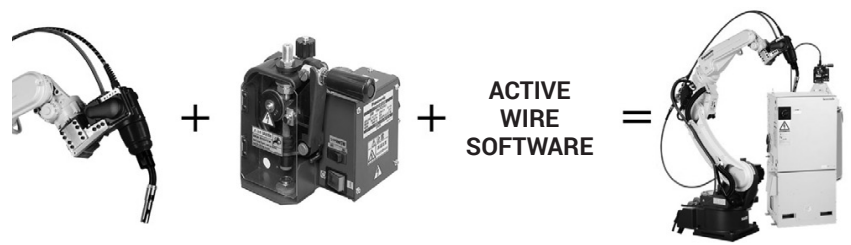

Rys. 5. System Active Wire - Aktywny proces podawania drutu firmy PANASONIC

Fig. 5. Active Wire system - PANASONIC Push-pull system of wire feeding

Na system TAWERS ACTIVE WIRE (rys. 5) składa się standardowy system TAWERS MAG, uchwyt spawalniczy Servo Pull z aktywnym podawaniem drutu (rys. 5), jednostka Wire Booster (rys. 5) oraz dedykowane oprogramowanie.

TAWERS ACTIVE WIRE pozwala na spawanie stali drutem litym o średnicy od 0.8 do $1.2 \mathrm{~mm}$ prądem do $350 \mathrm{~A} w$ cyklu P60\% oraz drutami proszkowymi [4]. Najlepsze rezultaty uzyskuje się w zakresie prądowym do 200A. Ideą układu jest uchwyt spawalniczy Servo Pull, który powtarza z dużą częstotliwością ruch wysuwania i cofania drutu zapewniając stały krótki cykl łuku spawalniczego, co ogranicza ilość odprysków. Bardzo istotną częścią całego systemu jest urządzenie Wire Booster do wspomagania podawania drutu. Urządzenie to montowane jest bezpośrednio na beczce $z$ drutem lub na kasecie szpuli z drutem, gdzie poprzez prowadnik spiralny doprowadza płynnie drut do uchwytu spawalniczego.

Połączenie znanej metody SP-MAG pochodzącej z systemów TAWERS oraz kontroli podawania drutu umożliwiło powstanie nowej innowacyjnej technologii TAWERS ACTIVE WIRE. Metoda AWP dzięki aktywnemu podawaniu drutu zmniejsza odkształcenia i naprężenia spawalnicze. Ograniczenie ilości odprysków jest możliwe dzięki kontroli sekwencji odrywania kropli płynnego metalu oraz gwałtowne obniżenie wartości prądu wyjściowego. Stabilizacja łuku poprzez ciągłą zmianę prędkości podawania drutu zapobiega nieregularnemu skracaniu drutu, co w przeciwnym wypadku prowadzi do generacji odprysków.

W standardowym systemie TAWERS SP-MAG (rys. 6a) zmiana wolnego wylotu elektrody powoduje powstawanie rozprysków w momencie przejścia z jednego materiału na drugi, natomiast w przypadku AWP (rys. 6b) [5] skrócenie lub wydłużenie wolnego wylotu elektrody nie powoduje powstawania rozprysków, a proces spawania pozostaje stabilny. Również duża zmiana kąta natarcia palnika nie powoduje utraty stabilnego łuku, a w ekstremalnym przypadku generuje jedynie znikomą ilość odprysków (rys 7.).

System AWP znakomicie sprawdza się przy spawaniu spoin obwodowych w zakresie od 0 do $360^{\circ}$ gdzie wymagane jest najpierw ciągnięcie palnika, a następnie jego pchanie. Firma TECHNIKA SPAWALNICZA system ACTIVE WIRE wdrożyła z powodzeniem w firmach branży motoryzacyjnej, przy produkcji łóżek szpitalnych i mebli stalowych (foteli i kanap). Na rysunku 8 przedstawiono system zrobotyzowany z modułem AWP do produkcji układów wydechowych samochodów osobowych.

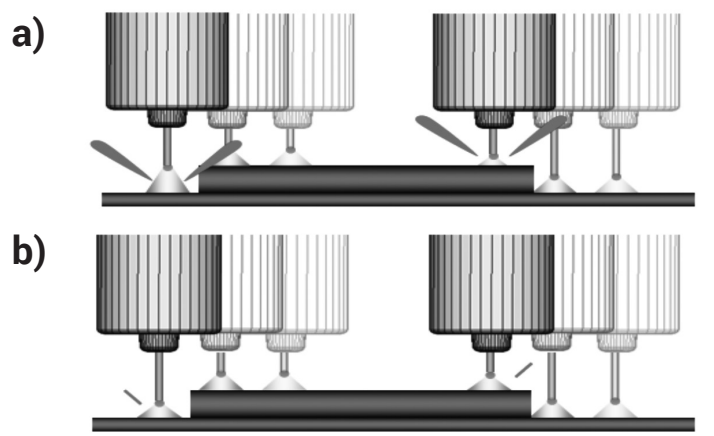

Rys. 6. Moment przejścia podczas procesu spawania z jednego materiału na drugi; a) standardowy system, b) system Active Wire Fig. 6. Passing for one material to another during the welding process; a) standard system, b) Active Wire system
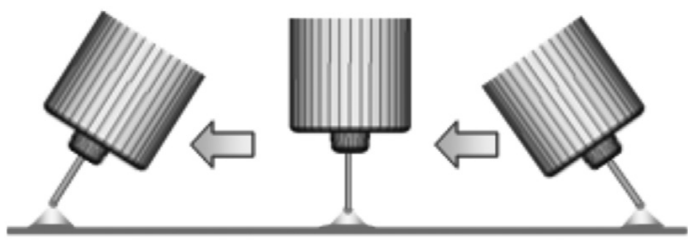

Rys. 7. Zmiana kąta natarcia podczas spawania w metodzie Active Wire Process nie powoduje powstawania odprysków

Fig. 7. Change of welding angle during welding process does not generate spatters in Active Wire Process method

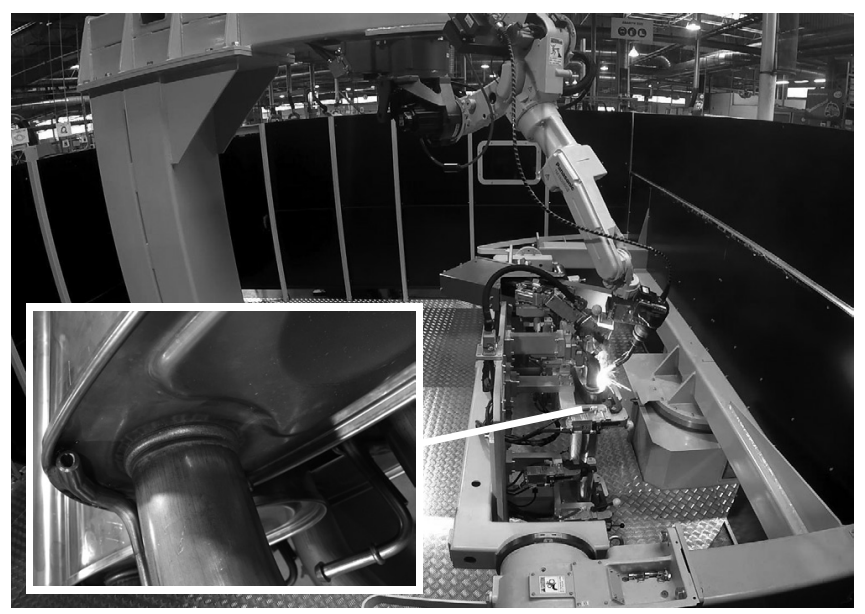

Rys. 8. Stanowisko spawalnicze z robotem PANASONIC serii TM oraz systemem Active Wire

Fig. 8. Welding station with PANASONIC TM robot and Active Wire system 


\section{Głowica do spawania TIG - 7 oś obrotowa}

Przy zrobotyzowanym spawaniu elementów cienkościennych wykorzystywana jest powszechnie metoda TIG, posiadająca szereg zalet względem metody MAG. Możliwe dzięki niej jest spawanie prądem o niskim natężeniu, a tym samym uzyskanie bardzo wąskiego i estetycznego wizualnie lica spoiny. Dodatkowo jeżeli jest taka konieczność, TIG pozwala na zrezygnowanie z podawania stopiwa w procesie i spawanie jedynie nietopliwą elektrodą korzystając wyłącznie z materiału rodzimego. Taką metodę wykorzystuje się głównie w złączach czołowych i przylgowych lub przy wykonywaniu spoin sczepnych. Spawanie metodą TIG z podawaniem dodatkowego spoiwa może nastręczać szereg trudności. Główną z nich brak precyzyjnego umiejscowienia drutu w jeziorku spawalniczym w trakcie wykonywania procesu. Standardowe palniki TIG wykorzystywane w robotyce posiadają zamocowany na stałe prowadnik drutu bez możliwości obracania go podczas procesu spawania [6]. Alternatywą jest innowacyjny palnik z dodatkowa osią obrotową firmy PANSONIC. Dodatkowy servo napęd, nazywany 7 osią - zlokalizowany jest bezpośrednio przy palniku robota, umożliwia obrót prowadnika podającego drut spawalniczy pod określonym kątem. Jego obrót w zakresie +/- 120 stopni zadawany jest bezpośrednio z panelu uczenia robota, rysunek 9 . Technologia ta została wykorzystana do spawania aluminiowych profili w firmie SUN GARDEN - jednego z największych producentów mebli ogrodowych w Polsce. TECHNIKA SPAWALNICZA Poznań zainstalowała tam trzy stanowiska z robotami wyposażonymi w 7 oś obrotową do spawania metodą TIG aluminiowych krzeseł ogrodowych (rys. 10). Rozwiązanie z 7 osią obrotową znalazło także zastosowanie $\mathrm{w}$ firmie PROFIM Turek przy produkcji stalowych krzeseł (rys. 11).
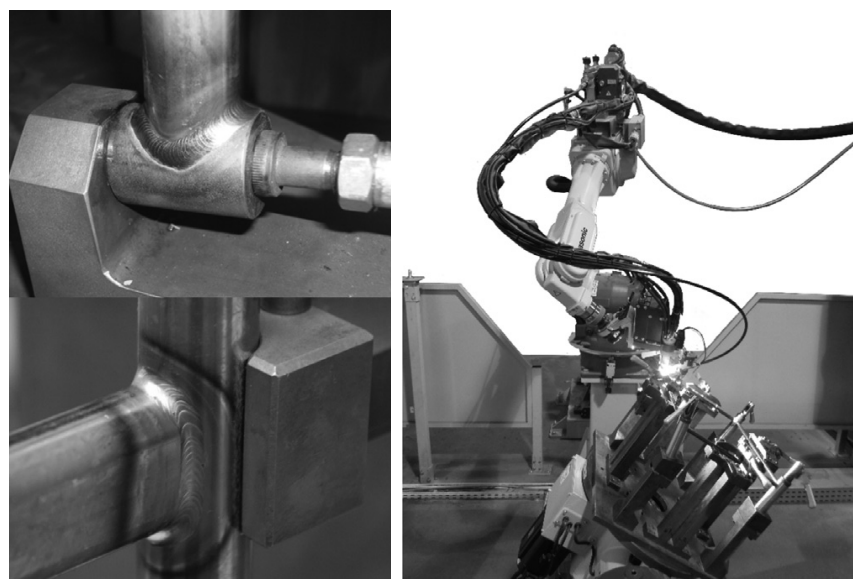

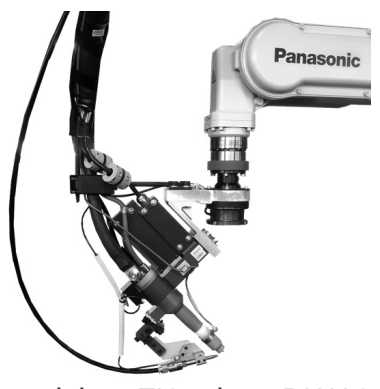

Rys. 9. Głowica spawalnicza TIG robota PANASONIC z dodatkową 7 osią obrotową podającą drut

Fig. 9. TIG welding head of PANASONIC robot with additional $7^{\text {th }}$ rotational axis for wire feeding

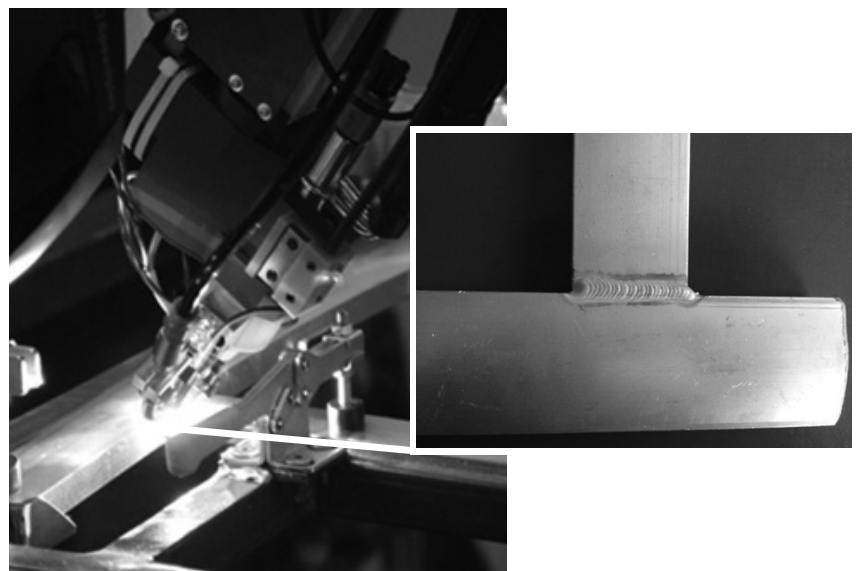

Rys. 10. Spawanie aluminiowych profili metodą TIG AC z wykorzystaniem 7 osi obrotowej PANASONIC

Fig. 10. TIG AC method for welding aluminum profiles using PANASONIC 7th rotational axis

Rys. 11. Spawanie obwodowe stalowych rurek metoda TIG DC z wykorzystaniem 7 osi obrotowej PANASONIC

Fig. 11. Orbital welding of steel pipes with TIG DC method using PANASONIC $7^{\text {th }}$ rotational axis

\section{Wnioski}

1. Zastosowanie robotów nowej generacji serii TM firmy PANASONIC umożliwia płynne, bezoporowe podawanie drutu, co znacznie zmniejsza ilość niezgodności spawalniczych

2. Zastosowanie innowacyjnej aplikacji ACTIVE WIRE PROCESS rozszerza możliwości zastąpienia mało wydajnej technologii TIG technologią MAG.

3. Zastosowanie głowicy TIG z 7-osią ułatwia wysokojakościowe spawanie TIG (AC/DC) elementów rurowych przenikających się (ekskluzywnych mebli, układów wydechowych samochodów osobowych, łóżek szpitalnych).

\section{Literatura}

[1] Nowak M., Buchowski J., Jędrzejak K., Wiśniewski D., Zastosowanie robotów spawalniczych w produkcji bram przemysłowych na przykładzie wdrożenia w firmie Wiśniowski, Przegląd Spawalnictwa 5/2015/

[2]. Materiały firmy PANASONIC.

[3]. Nowak M., Wiśniewski D., Czeladziński Ł., TAWERS AWP Active Wire Process - innowacyjna metoda spawania MAG cienkich elementów stalowych, Przegląd Spawalnictwa 5/2011.
[4]. Nowak M., Jędrzejak K., Automatyzacja i robotyzacja procesów spawania i paletyzacji w branży motoryzacyjnej, Przegląd Spawalnictwa 1/2016.

5]. Nowak M., Wiśniewski D., TAWERS - Nowa Generacja Robotów Spawalniczych Firmy PANASONIC, Przegląd Spawalnictwa 8/2011.

[6]. Nowak M., Wiśniewski D., Nowak T., Możliwości zastosowania metody TIG w systemach zrobotyzowanych, Przegląd Spawalnictwa 2/2008. 